\title{
O PAPEL DA MEMÓRIA INSTITUCIONAL PARA A GESTÃO UNIVERSITÁRIA: CONTRIBUIÇÕES PARA A CONSOLIDAÇÃO DA UMMA NA UFSCAR
}

\author{
THE ROLE OF THE INSTITUTIONAL MEMORY FOR \\ UNIVERSITY MANAGEMENT: CONTRIBUTIONS FOR \\ THE CONSOLIDATION OF UMMA IN UFSCAR
}

\author{
Samanta do Pradoa \\ Luciana de Souzab \\ Luzia Sigoli Fernandes Costac
}

\begin{abstract}
RESUMO
Introdução: Este trabalho propõe possíveis relações entre a gestão universitária e a memória. Mais especificamente, ressalta a contribuição da Memória Institucional (MI) como um elemento relevante para sustentar ações de gestão. A Universidade Federal de São Carlos (UFSCar), no contexto da consolidação de sua política de informação, comunicação e memória, cria, em 2017, a Unidade Multidisciplinar de Memória e Arquivo Histórico (UMMA). Essa iniciativa exemplifica a valorização da salvaguarda da Memória Institucional por parte da gestão universitária. Objetivo: O objetivo desta pesquisa é refletir sobre os elementos que possam subsidiar a identificação e a salvaguarda da MI, tendo em vista a consolidação da UMMA na UFSCar. Metodologia: O método adotado é do tipo exploratório e descritivo, com base em uma abordagem bibliográfica e documental. Foram analisadas três tipos de fontes: (1) a literatura científica sobre a temática; (2) documentos institucionais da UFSCar relacionados à política de memória e a criação da UMMA; e (3) um levantamento de informações de universidades federais brasileiras, sobre suas iniciativas relacionadas à MI. Resultados: Como principais elementos, foram identificados: nomenclatura, vínculo e coleções. As iniciativas identificadas possuem nomenclaturas distintas, e estão vinculadas a diferentes setores das universidades. As coleções ligadas à MI são variadas em formato e suporte. Conclusões: Os resultados obtidos ilustram possíveis contribuições para a consolidação da UMMA, bem como desta enquanto referência para outras universidades, demonstrando como a salvaguarda da MI pode contribuir para a criação de estratégias vinculadas ao desenvolvimento da instituição.
\end{abstract}

a Mestranda do Programa de Pós-Graduação em Ciência, Tecnologia e Sociedade da Universidade Federal de São Carlos (UFSCar). E-mail: samanta_prado@hotmail.com

b Doutora em Ciência da Informação pelo Instituto Brasileiro de Informação em Ciência e Tecnologia e Universidade Federal Fluminense. Docente permanente no Programa de Pós Graduação em Ciência, Tecnologia e Sociedade da Universidade Federal de São Carlos (UFSCar). E-mail: lugracioso@yahoo.com

c Doutor em Ciência da Informação pela Universidade Estadual Paulista Júlio de Mesquita Filho (UNESP). Professor da Universidade Federal de São Carlos (UFSCar). E-mail: luziasigoli@gmail.com 
Descritores: Gestão Universitária. Memória Institucional. Universidades Federais.

\section{INTRODUÇÃO}

A gestão universitária apresenta objetivos e compromissos diversos e conta com uma variedade de setores responsáveis por planejar, desenvolver e aplicar estratégias organizacionais e institucionais. Ainda que contenha elementos de caráter mais corporativo, podemos inferir que a gestão universitária se apresenta de uma forma mais complexa se comparada a de outras organizações. Entre suas características, apontamos: os objetivos múltiplos, entre esses, ser voltada para ensino, pesquisa e extensão; seu alto nível de especialização funcional, em sua maioria, docentes e servidores com elevado grau educacionais; a sua função de prestadora de serviços à população, consequentemente seu papel de transformação decorrente de seu caráter de transmissão e produção cultural e científica.

A estrutura universitária tem como alicerce Estatutos, Regimentos, Planos de Desenvolvimento (DESIDERIO; FERREIRA, 2004), entre outros documentos institucionais, que permitem que seus objetivos sejam elaborados e desenvolvidos. Assim como outras instituições, a universidade sofre influências externas (de ordem política, social, econômica, cultural) o que acarreta constantemente impactos em sua estrutura, na forma de como o planejamento e a gestão serão conduzidos.

Em todo o processo que envolve sua estruturação organizacional, a gestão universitária conta com a participação de diversos atores, setores acadêmicos (pedagógicos), serviços administrativos, documentos institucionais (ofícios, portarias), bem como outros elementos que contribuem para seu funcionamento (MATOS, 2004). Da mesma forma, ela é marcada pela responsabilidade de seguir decisões e diretrizes, em consonância com o que foi desenhado pelo seu colegiado, seus planos, projetos e sua capacidade orçamentária.

Nesse contexto, pode-se considerar a Memória Institucional (MI) como um elemento relevante para subsidiar ações da gestão universitária. $O$ objetivo 
desta pesquisa é refletir sobre os elementos que possam subsidiar a identificação e a preservação da Ml, tendo em vista a consolidação da Unidade Multidisciplinar de Memória e Arquivo Histórico (UMMA) da Universidade Federal de São Carlos (UFSCar). Dessa forma, pretende-se contribuir com a gestão universitária, por meio de elementos relacionados à Ml. O problema da pesquisa gira em torno das seguintes questões: (1) Quais elementos podem auxiliar para que possamos subsidiar ações de identificação e salvaguarda da memória institucional? (2) Em que medida estes elementos podem contribuir teoricamente e metodologicamente para a consolidação da UMMA?

As seções seguintes apresentam o referencial do trabalho, tanto bibliográfico quanto documental, em torno das seguintes temáticas: o conceito de Memória Institucional; a fundação da UFSCar, seu Plano de Desenvolvimento Institucional (PDI) e sua proposta para a UMMA, criada em 2017. Na sequência, é apresentada a metodologia da pesquisa e os principais resultados obtidos.

\section{MEMÓRIA INSTITUCIONAL}

O conceito de memória é básico para possibilitar a reflexão sobre memória institucional. Segundo Le Goff (2003), a memória nos remete a um conjunto de funções psíquicas pelas quais o ser humano utiliza ou representa informações referentes ao passado. Esse conjunto de funções psíquicas não deve, no entanto, ser associado unicamente à memória individual. Esse processo de recuperação e representação do passado acontece a partir das funções cognitivas individuais, mas se desenvolve por meio das relações sociais. Para Le Goff (2003), a preservação da memória social é fundamental para a história, assim como todo o seu processo, seja de limitar ou de ampliar a informação.

Para Halbwachs (2006) a memória é um saber criado e socialmente construído. Ela é mais ampla que as lembranças de um único indivíduo, podendo ser associada ao resgate e à preservação do passado social, um passado vivido coletivamente. No entanto, a memória não está ligada apenas ao passado, ela pode ser associada também ao presente e ao futuro. 
Com base nos estudos de Icléia Thiesen (2013), a memória é um elemento fundamental para o funcionamento das instituições. Por meio da memória, as instituições podem reter as informações que interessam para seu funcionamento. Particularmente, o conceito de Memória Institucional (MI), é tido como um conceito híbrido, pois ele trabalha tanto na esfera da memória quanto das instituições. A Ml é uma memória que não é construída só internamente, ou seja, as informações provêm tanto de dentro quanto de fora da instituição. A MI, segundo Thiesen (2013), está em constante evolução, pois é elaborada com o passar do tempo, sendo o reflexo de uma trajetória social e histórica. Pensando na universidade, sua memória se torna um elemento importante para a comunidade interna e externa e para o processo de construção da própria instituição.

O que podemos inferir é que a $\mathrm{Ml}$ concebida por uma universidade detêm, em sua forma e conteúdo, informações que remetem a sua trajetória. Essa trajetória agrega tanto as características da universidade como uma instituição de conhecimento, de saberes, que é legitimada e sustentada pela sociedade, quanto os elementos de caráter estratégico, que possibilitam o seu planejamento, seja de médio e longo prazo (MATOS, 2004). O que temos é que a $\mathrm{MI}$, longe de ser apenas um resgate do passado, pode ganhar um papel de destaque em todo o proceso organizacional, auxiliando a universidade a atingir seus objetivos e metas.

A manutenção e a preservação da $\mathrm{Ml}$ possibilitam que a gestão universitária realize avaliações, diagnósticos e implementações, tendo em vista a consolidação de seus objetivos, de suas atividades institucionais, seus setores e serviços. Em outros termos, a MI pode contribuir para manter a instituição mais dinâmica e viva, além de orientar a continuidade de suas funções e objetivos.

\section{A UFSCAR, O PDI E A UMMA}

\subsection{A FUNDAÇÃO DA UFSCAR}


Podemos destacar que, para que haja a preservação e manutenção da $\mathrm{MI}$, é preciso que as universidades criem condições para isso. No Brasil, algumas universidades federais implementaram, ao longo do tempo, ações ou políticas voltadas para o desenvolvimento de sua MI. Particularmente, no caso da Universidade Federal de São Carlos (UFSCAR, 2018) a instituição vem se mobilizando mais intensamente a partir de 2010, embora se perceba que sempre houve uma preocupação nesse sentido.

A UFSCar foi criada em 22 de maio de 1968, pelo Decreto $n^{\circ} 62.758$, embora a sua criação já houvesse sido promulgada pela Lei 3.835, de 13 de dezembro de 1960, junto com a federalização da Universidade da Paraíba, sendo que suas atividades efetivas tiveram início em 13 de março de 1970, nas instalações da antiga Fazenda Trancham, em São Carlos. A UFSCar foi a primeira universidade federal criada no Estado de São Paulo e a única, até o momento, localizada no interior do Estado. Atualmente possui quatro campi nas cidades de São Carlos, Araras, Sorocaba e Lagoa do Sino (UFSCAR, 2018).

Historicamente, podemos apontar que a UFSCar foi instituída como uma fundação no auge do regime militar-autoritário brasileiro (1968), assim como outras instituições federais que surgiram na mesma época. Sguissardi (1993) buscou analisar a história da UFSCar desde a sua criação. Um dos aspectos da UFSCar, apontados é seu modelo de fundação. A fundação tem uma tendência descentralizadora, ao contrário do modelo de autarquia, que é centralizado (SGUISSARDI, 1993).

De acordo com o decreto instituidor do Estatuto da Fundação (1968) (SGUISSARDI, 1993), da Fundação Universidade Federal de São Carlos (FUFSCar), é estabelecido que a instituição terá o Reitor da Universidade como o Presidente da Fundação. Entre outros pontos importantes que o Estatuto traz, podemos destacar: as competências do presidente da Fundação; o Patrimônio e o Regime Financeiro; o Conselho de Curadores e suas competências; e, principalmente, o objetivo de manter a universidade como uma instituição voltada para o ensino, pesquisa e extensão, presente até os dias atuais. 


\subsection{PDI: Contexto, Estratégias e Centro de MemóRia}

O PDI é voltado para a criação de estratégias e dispositivos normativos que caracterizam o funcionamento das Instituições de Ensino Superior (IES), no Brasil, tendo em vista alcançar os objetivos da instituição. (DESIDERIO; FERREIRA, 2004).

Vale ressaltar que o PDI, legalmente, teve como base para sua elaboração a Lei 10.861 (BRASIL, 2004), a mesma que oficializou o Sistema de Avaliação do Ensino Superior (SINAES) em 2004. A partir dos objetivos do SINAES nasce a ideia da criação de um planejamento voltado para as IES brasileiras e de avaliação sistemática de suas ações, definida por meio da Portaria $n^{\circ} 300$ (BRASIL, 2006b) Essa portaria reconhece o PDI como um documento institucional que, entre outros pontos, diz respeito a seus dispositivos legais, missão da instituição, organização institucional, planejamento, avaliação, diretrizes para os projetos pedagógicos, abrangendo um período de 5 anos de duração. Um novo avanço ocorre com a publicação do Decreto $n^{\circ} 5.773$ (BRASIL,2006a), cujo art ${ }^{\circ} 16$, possibilita que o PDI possua uma nova estrutura, bem como novos procedimentos a serem elaborados e analisados.

A proposta de elaboração do PDI da UFSCar, apresentada inicialmente em 2002 pelo Conselho Universitário (ConsUni), teve como motivação o término do Plano Diretor elaborado em 1985 (UFSCAR, 2004), com suas metas alcançadas. O PDI da UFSCar, cuja elaboração teve início em 2011, sendo finalizado e aprovado pelo ConsUni em 2013, foi estruturado em três grandes aspectos: Acadêmicos, Organizacionais e Físico-Ambientais. De forma geral, o PDI da UFSCar é construído coletivamente com a comunidade interna e externa, e tem como base eixos de informações transversais decorrentes do cotidiano institucional, das análises institucionais, das avaliações, das políticas pedagógicas institucionais, entre outras, que viabilizem a criação de estratégias, bem como orientem as ações e decisões institucionais (UFSCAR, 2004).

Entre suas Diretrizes, com relação à memória da instituição destaca-se, entre as Diretrizes Específicas apresentadas, o item 3.6 (Artes, Cultura e 
Comunicação), que se desdobra em três subitens, relacionados com as finalidades deste estudo, sendo eles:

3.6.2 Promover a compreensão da gestão da informação, comunicação e memória como transversal à Universidade, como temas estratégicos e prioritários para a gestão da Instituição, criando e mantendo política de investimento em pessoal e recursos financeiros, bem como de captação de recursos externos, que viabilize a atuação estratégica da UFSCar em Artes, Cultura e Comunicação;

3.6.38 Elaborar e implementar política de preservação da memória institucional e de suas relações com a memória da Educação, Ciência, Tecnologia e Cultura;

3.6.39 Criar e manter condições infraestruturais, financeiras e de pessoal para o funcionamento de um centro de memória voltado à preservação e à disseminação do patrimônio da Universidade, da Educação e da Ciência e Tecnologia. (UFSCAR, 2013, p. 3133)

Com base na análise dessas Diretrizes Especificas do PDI, temos que a MI torna-se um elemento importante, como já dito, um fator estratégico para a gestão universitária. A elaboração, a implementação de políticas e de unidades voltadas para preservação e manutenção do seu patrimônio, da sua produção científica, tecnológica e administrativa, ou seja, da sua MI, são tidos como fatores importantes para o desenvolvimento de suas ações de planejamento e atividades institucionais.

O desenvolvimento de um Centro de Memória ( $\mathrm{CM}$ ), como postulado pela diretriz específica 3.6.39, vem a ser uma estrutura importante a fim de contribuir para a criação de estratégias para a gestão universitária. De forma geral, compreendemos o $\mathrm{CM}$ como uma reunião, marcada pelo diálogo e pela interconexão, entre os elementos de resgate, avaliação, tratamento técnico e preservação de um acervo heterogêneo, relacionado ao conhecimento e às informações relativas à vida da instituição, nesse caso pública (CAMARGO; GOULART, 2015). Essa interdisciplinaridade, presente em suas atividades, conjuntamente com o seu caráter híbrido, caracteriza o Centro de Memória da seguinte forma: "Centro" significa uma unidade de articulação e controle, de não fragmentação; "Memória" significa uma ideia de repositório, ou seja, de armazenamento das informações que estão contidas nos documentos da instituição. 
No CM há uma continuidade de esforços e ações voltados para a acumulação de documentos, relacionados à finalidade de organizar a maioria do material produzido ao longo da história da instituição. Esses documentos são voltados não só para o passado, mas para o futuro e o presente. Segundo Camargo e Goulart (2015), no cenário atual dos CM, tanto públicos quanto privados, o agrupamento de documentos de uma determinada instituição é um elemento probatório do seu funcionamento, de suas atividades, de seus serviços. No caso específico das universidades, esses aspectos podem ser verificados por meio: das atas de reuniões de conselhos, com as participações de docentes, discentes e pessoal técnico-administrativo; da consolidação de editais e outros documentos voltados para o ensino, pesquisa e extensão; dos processos administrativos relacionados à contratação ou/e rescisão de serviços; entre outros. Esses documentos probatórios têm a intenção de gerar informação sobre a própria instituição, a fim de produzir conhecimento em virtude de seus objetivos, sejam eles coorporativos, organizacionais ou até mesmo intelectuais.

No caso das universidades, o capital intelectual é o que rege seu funcionamento mais que os outros capitais (corporativo, empresarial). $\mathrm{O}$ foco principal de um centro de memória são os documentos relacionados às atividades-fim da instituição a que pertence (ou seja, aquelas atividades relacionadas aos objetivos principais da instituição, seja por meio de produtos ou serviços). O CM considerará que arquivos, bibliotecas e museus se apresentam também como produtores desse capital intelectual.

Essas três entidades, cada qual com sua particularidade, metodologia, objetivo e técnica (CAMARGO; GOULART, 2015), historicamente são capazes de gerar, reunir, armazenar e disponibilizar a informação, permitindo o acesso por diversos setores, possibilitando que a informação ali contida via documento torne-se matéria-prima para a construção de uma memória de cunho institucional, ou seja, segundo Camargo e Goulart (2015, p. 71):

Há documentos de todos os gêneros: textuais, audiovisuais, sonoros, iconográficos, além de objetos e artefatos. No caso de organizações que produzem para o varejo, o centro de memória costuma incorporar embalagens e material de divulgação e propaganda de diversos tipos e formatos. Mas há também 
documentos representativos de outras atividades: maquetes e plantas; boletins de circulação interna; relatórios de prestação de contas; relatórios de sustentabilidade; troféus, medalhas e placas de homenagem, notícias e reportagens fotográficas relacionadas e eventos importantes. (...) Cabe mencionar, finalmente, a presença de documentos de caráter técnico e especializado, que servem de apoio às atividades da organização: ensaios, teses, artigos científicos, sondagens de opinião, indicadores econômicos, coletâneas de legislação, informes e muitos outros.

Os centros de memória visam preservar os elementos capazes de reconstituir a trajetória da instituição e na mesma medida, fornecer elementos para que a instituição se projete no futuro.

\subsection{A UMMA: Salvaguarda da MEMÓRIA da UFSCAR}

A UFSCar cria em 11 de maio de 2017, por meio da portaria GR n 242, considerando a resolução do ConsUni, $n^{\circ} 870$, a Unidade Multidisciplinar de Memória e Arquivo Histórico (UMMA), esta vinculada ao Gabinete da Reitoria. A UMMA tem como finalidade garantir o registro, a guarda, a organização, e o acesso da memória na UFSCar, bem como seu patrimônio cultural.

O processo administrativo para a criação da UMMA foi iniciado em setembro de 2016. A Pró-reitora de Extensão (PROEX) da UFSCar, por meio de seu ofício Of. PROEX n ${ }^{\circ}$ 119/2016 solicita ao reitor o pleito da criação da UMMA. Essa solicitação já havia sido deliberada pelo Conselho de Extensão na $82^{a}$ Reunião Ordinária do dia 15/09/2016, que como resultado da apresentação do Relatório da Comissão de Memória, constatou a necessidade da continuidade de trabalhos na área, bem como da criação de uma política voltada para essa temática. Complementar a esse documento, temos o Ofício SPDI nº34/2016 da Secretaria Geral de Planejamento e Desenvolvimento Institucionais (SPDI) que enfatiza a importância do $1^{\circ}$ Seminário de Informação, Comunicação e Memória da UFSCar, que aconteceu em 2010, e das contribuições advindas do Grupo de Trabalho (GT) desse evento, ou seja, "Contribuições para a estruturação da unidade multidisciplinar de memória e arquivo histórico na UFSCar". Ressalta também a importância da continuidade do trabalho, solicitando apoio institucional para esse fim. Segundo as propostas idealizadas 
por meio das sínteses de discussão do GT anteriormente mencionado, foi proposto o seguinte objetivo principal para a UMMA: preservar a memória, a história sociocultural evidente no patrimônio (material e imaterial) da UFSCar. Entre os principais objetivos específicos definidos segundo a resolução do ConsUni, nº 870 de 2017 :

\begin{abstract}
1).promover a integração de estudos e pesquisas inter multi e trans disciplinares visando desenvolver teorias e boas práticas para identificação, conservação, organização e disponibilização dos acervos e coleções históricas da UFSCar; 2) identificar e organizar os acervos, de natureza histórica, sejam eles bibliográficos, iconográficos, documentais, filmográficos, sonoros, cartográficos e museológicos e outros, produzidos pela UFSCar ao longo de sua história; 3) promover um espaço de interação, convivência, garantindo à comunidade, interna e externa, o acesso e a fruição dos bens culturais gerados pela UFSCar.
\end{abstract}

Para que esses objetivos sejam alcançados, e dessa forma se iniciem as ações da unidade, é estabelecida a criação de grupos e subgrupos de trabalho, com estudos e pesquisas de forma multi/inter/transdisciplinar. A expectativa dessa iniciativa é resultar tanto na criação de teorias quanto de boas práticas relacionadas à memória. Entre esses elementos, apontamos: 1) o próprio estabelecimento de critérios a fim de identificar o valor histórico das coleções e documentos; 2) o estabelecimento de espaços e técnicas de conservação de diversas coleções; 3) após a identificação dessas coleções, o próprio desenvolvimento de metodologias que visem a organização das mesmas; 4) a disponibilização de acervos e coleções históricas, tendo em vista seu acesso e proveito dos bens que foram produzidos pelas instituição; 5) a criação de espaços de formação; e 6) a realização de outras atividades relevantes, importantes para o desenvolvimento da unidade de memória.

Podemos dizer que a variedade de ações proporcionada pela UMMA condiz com a própria ideia de uma universidade e sua missão. Particularmente, no caso de uma universidade pública como a UFSCar, pode destacar seu compromisso social de desenvolvimento de conhecimento científico, cultural e educacional, Em outros termos, por meio do acesso à memória institucional da universidade, a UMMA pode vir a possibilitar a criação de estratégicas 
institucionais a fim de auxiliar sua gestão universitária, bem como uma democratização do acesso ao conhecimento pela sociedade.

\section{METODOLOGIA}

Considerando o objetivo desse trabalho, o método adotado é do tipo exploratório e descritivo, com base em uma abordagem bibliográfica e documental. Metodologicamente. a escolha da realização de uma pesquisa exploratória tem como intenção obter maior familiaridade com o campo da pesquisa (GIL, 2010), para que se tenha uma visão geral da temática estudada, uma vez que a literatura sobre o tema é escassa.

A dimensão exploratória desta pesquisa teve como base o levantamento de informações de oito universidades federais brasileiras, sobre suas iniciativas relacionadas à Ml. Essas informações foram obtidas por meio de consultas aos sites institucionais ${ }^{1}$ de cada uma das seguintes universidades: Universidade Federal de Goiás (UFG), Universidade Federal da Bahia (UFBA), Universidade Federal do Ceará (UFC), Universidade Federal do Maranhão (UFMA), Universidade Federal do Acre (UFAC), Universidade Federal do Rio de Janeiro (UFRJ), Universidade Federal de Lavras (UFLA) e Universidade Federal do Rio Grande do Sul (UFRGS). A intenção dessa consulta foi identificar algumas das iniciativas já existentes de salvaguarda da memória institucional, no contexto das Instituições de Ensino Superior (IFES) no Brasil. Para essa consulta, foram utilizadas oito palavras-chave, pertinentes ao tema pesquisado: memória científica, memória institucional, lugares de memória, centro de memória, arquivo, museu, unidade de memória e divisão de memória. Essas palavras foram identificadas durante a leitura dos textos teóricos, e eventualmente após as pesquisas iniciais nos sites das universidades. Consideramos que tal pesquisa exploratória pode oferecer subsídios para a consolidação das iniciativas ligadas à MI no contexto da UMMA na UFSCar.

\footnotetext{
1 Todos os sites institucionais consultados constam referenciados na seção de resultados.
} 
A partir desse ponto, adotamos uma abordagem descritiva: por meio da análise dos sites dessas instituições, descrevemos tanto a forma como foram feitas as buscas, quanto os principais elementos analisados: as nomenclaturas (as palavras-chave mais identificadas), os vínculos (o tipo de vínculo institucional que caracteriza as iniciativas relacionadas à $\mathrm{MI}$ ) e as coleções (os principais tipos de coleções identificadas). Para o embasamento desse procedimento foi realizado tanto um estudo bibliográfico quanto documental.

A pesquisa bibliográfica se pauta na literatura científica que trata dos conceitos de gestão universitária, planejamento institucional, memória institucional e centro de memória. Já a pesquisa documental abre a possibilidade de se trabalhar com documentos institucionais que façam menção à memória das instituições de ensino, pesquisa e extensão, como por exemplo: decretos, estatutos, processos, regimentos, portarias, ofícios, notícias, incluindo materiais que estejam disponíveis tanto em formato físico quanto on-line, por meio de sites institucionais das universidades que noticiam sobre a história da instituição e a preservação da sua memória. Para a realização desta pesquisa partimos do pressuposto de que a $\mathrm{Ml}$ tem um potencial estratégico para a gestão universitária.

\section{RESULTADOS E DISCUSSÕES}

\subsection{Descrição Geral dos Resultados das Buscas}

Como resultado da pesquisa exploratória, como descrito anteriormente, o uso das oito palavras-chave (memória científica, memória institucional, lugares de memória, centro de memória, arquivo, museu, unidade de memória e divisão de memória), possibilitou identificar algumas iniciativas relacionadas à MI por meio da busca nos sites das universidades selecionadas (UFG, UFBA, UFC, UFMA, UFAC, UFRJ, UFLA e UFRGS). Para definir o universo da pesquisa, utilizamos como critério a seleção de universidades que possuem iniciativas de reunião de coleções relacionadas à memória científica e institucional da universidade. 
As buscas foram feitas nos sites institucionais das universidades, e se necessário, no site de ferramenta de busca na internet Google. Algumas vezes, em algumas buscas realizadas, a identificação da existência de um "Memorial", um “Arquivo Central”, um "Museu Universitário", uma "Coleção de Memória”, uma "Divisão de Memória", entre outros, é obtida não de forma imediata, mas sim, por meio da leitura dos clippings, das noticias que compõem o resultado daquela busca. A identificação de tal "centro de memória" não acontece de forma simples, mas sim por meio de uma busca que muitas vezes vai além da busca principal no site ou na própria ferramenta de busca na internet. Como resultados da busca, foram selecionadas as páginas desses centros que fizessem menção à memória ou à identidade da universidade no corpo do texto das concepções.

Outro ponto a se debater é o uso de aspas ou não nas palavras-chave. Com a finalidade de exaustar a busca de resultados no site institucional, a fim de evitar recorrer ao Google, a busca inicialmente foi feita com o uso de aspas. Quando pouco ou quase nenhum resultado era obtido, foram retiradas as aspas dos vocábulos. Em alguns sites, como será relatado abaixo, foi sugerida a utilização de booleanos, ou seja, o uso de OR entre as palavras, por exemplo: "memória" OR "institucional". Esse recurso só foi usado quando já esgotadas as possibilidades de resultados nas buscas.

A seguir são descritas a forma como foram feitas as buscas, as palavraschave que mais obtiveram resultados e as formas de identificação do "centro de memória".

A UFG, localizada na região do Centro-Oeste, foi criada em 1960, e atualmente possui 4 regionais (Catalão, Jataí, Goiás e Goiânia) e 3 campi (Colemar Natal e Silva, Samambaia e Aparecida de Goiânia). A busca foi feita no site principal da universidade ${ }^{2}$, com o uso de todas as palavras-chave, obtendo resultado com a palavra-chave "Arquivo". No site institucional foi feita tanto a busca simples como a busca avançada, sem a utilização de aspas nos vocábulos. A identificação do Centro de Informação, Documentação e Arquivo (Cidarq) da UFG se deu por meio da leitura dos clippings obtidos com as buscas.

2Disponível em: https://www.ufg.br/. Acesso em: 01 jul. 2018. 
A UFBA, localizada na região Nordeste, historicamente iniciou suas atividades em 1808. Mas foi em 1950, como universidade federal, que teve suas atividades institucionalizadas em nível federal. A busca foi feita no site principal da universidade ${ }^{3}$, com o uso de todas as palavras-chave, obtendo retorno principalmente com os vocábulos: "Arquivo"; "Museus", "Lugares de Memória". No site institucional foi feita a busca simples com o uso de aspas nos vocábulos.

A busca pela palavra-chave: "Arquivo" obteve retorno como: Coordenação de Arquivo e Documentação - $C A D^{4}$, vinculado à Pró-Reitoria de Administração (PROAD); já do vocábulo "Museu", os museus: Museu de Arqueologia e Etnologia (MAE) $)^{5}$, Museu de Arte Sacra (MAS), Museu Afro Brasileiro - MAFRO. Para efeito desta pesquisa, ou seja, para fins de identificação de elementos da memória científica e institucional, escolhemos o resultado advindo da palavrachave: "Lugares de Memória". Segundo a informação do site, a coleção que está localizada no espaço Lugares de Memória da UFBA se apresenta de forma mais ampla. Ou seja, ela possui as seguintes unidades de memória: Estudos Baianos; Arquivo Histórico; Memorial UFBA.

Os Estudos Baianos são compostos por uma coleção de pesquisadores diversos e de outras personalidades que escreveram ou possuíram um acervo composto por livros, manuscritos, entre outros documentos textuais relacionados à Bahia; o Arquivo Histórico é composto por arquivos de cunho institucional e/ou pessoal. Em sua maioria são documentos relacionados a arquivos históricos importantes para o legado da história da Bahia; o Memorial UFBA é composto por um conjunto de bens materiais advindos de 12 acervos de personalidades Baianas, agregando também a produção técnica, científica, cultural, artística da UFBA e as publicações que foram editadas pela editora da universidade. Entre estes documentos há objetos tridimensionais, cartas, jornais, multimeios, livros, fotografias, itens decorativos, cartazes, folders, entre outros. A identificação do espaço Lugares de Memória da UFBA foi obtida nas buscas simples, mas

\footnotetext{
3 Disponível em: https://www.ufba.br/ . Acesso em: 01 jul. 2018.

${ }^{4}$ Disponível em: https://proad.ufba.br/CAD. Acesso em: 01 jul. 2018.

${ }^{5}$ Disponível em: http://www.mae.ufba.br/sobre/historia. Acesso em: 01 jul. 2018.
} 
também foi necessário fazer uma busca no Sistema Integrado de Bibliotecas (SIBI) no site institucional da universidade.

A UFC, localizada na região Nordeste do país, foi criada em 1954, atualmente é composta por 7 campi (Benifica, Pici, Porangabuxu - localizados na sede da UFC em Fortaleza - Sobral, Quixadá, Cratéus e Russas). A busca foi feita no site principal da universidade ${ }^{6}$, e foram utilizados todos os vocábulos. No site institucional foram selecionadas as opções para obtenção mais ampla de resultados, "Buscar Por: Todas as palavras", bem como a seleção das opções, no buscar somente, "Noticias", "Conteúdo institucional" e "Categorias". Nas palavras-chave, com destaque para a "Memória Institucional", não foram utilizadas as aspas, uma vez que com o uso de aspas obtinha-se poucos resultados. Vale frisar que a identificação da existência do Memorial da UFC se deu por meio da leitura dos clippings obtidos com a busca. A identificação das coleções com que o Memorial trabalha é obtida por meio do ícone da página "Área de Atuação". Entre as atividades apontam-se o desenvolvimento da elaboração de projetos voltados para a área museológica, arquivística e bibliográfica do Memorial, bem como a organização, o tratamento e a digitalização do acervo documental, iconográfico e bibliográfico.

A UFMA, localizada na região Nordeste do país, foi instituída em 1966 pelo Governo Federal, e atualmente possui 8 campi (São Luís, Bacabal, Codó, Pinheiro, São Bernardo, Chapadinha, Grajaú, Imperatriz e Balsas). A busca foi feita no site principal da universidade ${ }^{8}$, e foram utilizados todos os vocábulos, sem o uso de aspas. $O$ resultado foi obtido com a palavra-chave "memória institucional", na categoria "notícias". A identificação do Memorial Cristo Rei UFMA se deu por meio da leitura dos clippings obtidos com as buscas.

A federalização da UFAC concretizou-se no ano de 1974. A busca foi feita no site principal da universidade ${ }^{9}$, e foram utilizados todos os vocábulos com o uso de aspas. Os vocábulos com retorno maior foram "Memória Institucional", "Arquivo" e "Museu". Os dois primeiros trouxeram, como resultados, informações sobre o Arquivo

\footnotetext{
${ }^{6}$ Disponível em: http://www.ufc.br/. Acesso em: 01 jul. 2018.

7 Disponível em: http://www.memorial.ufc.br/sobre-o-memorial/areas-de-atuacao/ .Acesso em: 01 jul. 2018.

${ }^{8}$ Disponível em: http://portais.ufma.br/PortalUfma/index.jsf . Acesso em: 01 jul. 2018.

${ }^{9}$ Disponível em: http://www.ufac.brl .Acesso em: 01 jul. 2018
} 
Central da instituição. No entanto, a palavra "Museu" remete ao Museu Universitário, que mesmo não remetendo aos conceitos de memória científica e/ou institucional no corpo do seu texto, possui uma coleção museológica que remete à história da instituição, assim como outras coleções (textuais/documentais, iconográfica, científica). A identificação do Museu Universitário foi obtida nas buscas.

A UFRJ, localizada na região Sudeste do país, foi fundada em 1920 e é uma das universidades mais antigas do país. Ela dispõe de inúmeros museus, arquivos e centros de memória em sua estrutura. A busca das palavras-chaves foi feita no site principal da universidade ${ }^{10}$, com o uso de todos os vocábulos, e com uso de aspas na busca simples do navegador. Vale pautar que, de todos os vocábulos, a única busca que não obteve retorno foi com a palavra-chave "unidade de memória". Dos resultados obtidos com os demais, para efeito desta pesquisa, nos pautamos nas palavras-chave: "Memória Institucional" e "Divisão de Memória". A identificação da "Divisão de Memória Institucional"11 foi feita por meio da leitura dos clippings. A coleção dessa Divisão de Memória é composta, segundo o site, por: Coleção Memória da UFRJ, encontrada na página do Software Minerva/UFRJ, clicando na busca "Memória UFRJ-MUFRJ". Na busca efetuada é possível localizar documentos como: anais de eventos, livros, documentos, artigos, entre outros. Na opção "Lugares de Memória" há diversos links que direcionam a Museus, Centros de Documentação ou Memória, Arquivos, Núcleos de Memória, Programas de Estudos e Bibliotecas. Em "edificações tombadas", os prédios e o observatório que foram tombados como patrimônio histórico. Em "acervos", estes são compostos por documentos e vídeos institucionais. Em "memória oral", esta é registrada por meio de entrevistas. Em "imagens da UFRJ", encontramos informações sobre o uso do selo institucional, e menção a Títulos Honoríficos concedidos pela UFRJ.

A UFLA, localizada na região Sudeste do país, teve a sua federalização no ano de 1963. A busca das palavras-chave foi feita no site principal da universidade ${ }^{12}$, com o retorno do vocábulo "Museu" com o uso de aspas. A

\footnotetext{
10 Disponível em: https://ufrj.br/. Acesso em: 01 jul. 2018

11 Disponível em: https://memoria.sibi.ufrj.br/. Acesso em: 01 jul. 2018

12 Disponível em: http://www.ufla.br/portal/. Acesso em: 01 jul. 2018
} 
identificação do Museu Bi Moreira (MBM) foi feita mediante a leitura de clippings. É um museu que possui coleções científicas (etnográficas, arqueológicas), documentais (documentos textuais da instituição), iconográficas (fotografias) e museológicas (objetos tridimensionais). Para obter mais informações sobre o museu, uma vez que no site são poucas as informações encontradas sobre suas coleções, pode-se acessar a galeria de fotos ${ }^{13}$ do museu.

A UFRGS, localizada na região Sul do país, só passou a chamar Universidade Federal do Rio Grande do Sul no ano de 1950. A busca das palavras-chave foi feita no site principal da universidade ${ }^{14}$, com o uso de todas as palavras-chave, e com o uso de aspas. Duas dessas tiveram resultados condizentes com esta pesquisa: "Memória Institucional" e "Museu". A primeira, por meio das leituras dos clippings com informações sobre o LUME, o repositório Digital da instituição; e a segunda palavra-chave com o Museu da UFRGS.

Na descrição do Lume da UFRGS, há a indicação de que seu objetivo é reunir, preservar, divulgar e disponibilizar o acesso a documentos nos âmbitos acadêmico, científico, artístico e administrativo, estes que fazem parte da rotina, das atividades da universidade, assim como outros que fazem referência à instituição e suas coleções. Esses documentos são digitais em formatos como texto, imagem, vídeo e áudio. Ao lermos a descrição do Museu da UFGRS, as coleções remetem à história, à memória e à identidade da universidade e da cidade de Porto Alegre. Entre suas coleções ${ }^{15}$ são apontadas: coleções iconográficas, textuais/documentais e museológicas.

\subsection{SínTESE dos Resultados}

A partir da análise dessas oito universidades federais, foi possível identificar suas principais iniciativas relacionadas à $\mathrm{Ml}$, incluindo as nomenclaturas utilizadas, os vínculos institucionais dessas iniciativas e os tipos de coleções presentes em cada uma delas.

\footnotetext{
13 Disponível em: http://proec.ufla.br/campus-historico-e-museus/museu-bi-moreira/galeria-defotos. Acesso em: 01 jul. 2018

14 Disponível em: http://www.ufrgs.br/ufrgs/inicial .Acesso em: 01 jul. 2018

15 Disponível em: https://www.ufrgs.br/museu/acervo/. Acesso em: 01 jul. 2018.
} 
No caso das nomenclaturas, estas puderam ser identificadas por meio das palavras-chave que retornaram os resultados mais significativos nas buscas, e foram: Centro de Informação, Documentação e Arquivo (UFG), Lugares de Memória (UFBA), Memorial (UFC, UFMA), Museu Universitário (UFAC), Divisão de Memória Institucional (UFRJ), Museu (UFLA, UFRGS).

No caso dos vínculos, os centros de memória em questão estão, em sua maioria, vinculados ao Sistema Integrado de Bibliotecas (SIBI) e ao Gabinete do Reitor (GR) da Instituição. A subordinação a estas estruturas reflete a forma como a memória é desenvolvida, estruturada, e que tipos de profissionais estão ligados às suas atividades. Podemos inferir que, no caso do SIBI há o envolvimento de profissionais mais especificamente da área de Biblioteconomia; já no caso do Gabinete do Reitor, há uma composição mais diversificada.

No caso das coleções das universidades federais pesquisadas, quantitativamente, foram identificadas as seguintes coleções: textual/documental (8), coleção museológica (7), coleção iconográfica (6), coleção bibliográfica (4), coleção cientifica (3), coleção cartográfica (2) e as demais, coleção audiovisual, coleção arquitetônica e coleções artísticas e culturais (1).

A UMMA da UFSCar encontra-se em fase inicial de concepção de sua estrutura, a ser oportunamente apreciada pelo colegiado superior. A proposta de organograma foi elaborada por Costa (2017), coordenadora da UMMA, por ocasião de discussões na disciplina ${ }^{16}$ a ser ministrada durante o período em a mestranda A aula versava sobre a concepção de Centros de Memória de forma geral, apresentando seus objetivos, exemplos, e como tal, apresentava a possível estrutura do que virá a ser a UMMA.

\footnotetext{
${ }^{16}$ Aula ministrada na Disciplina: Gestão de Coleções e do Patrimônio em Unidades de Informação do Departamento de Ciência da Informação da UFSCar, no período de 21082017 a 20122017.
} 
Figura 1 - Proposta de organograma da UMMA

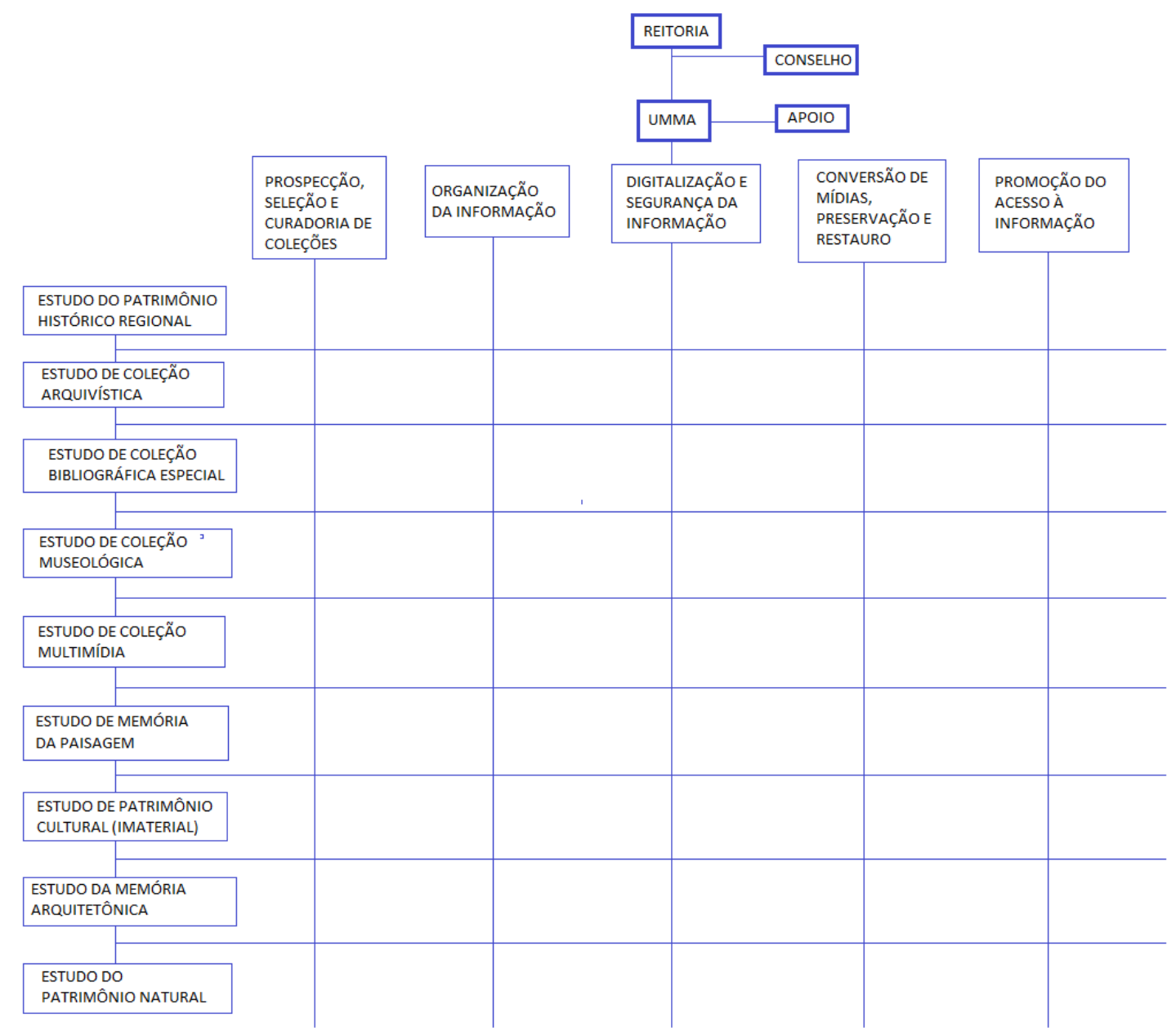

Fonte: Costa (2017)

Na Figura 1, vemos os principais estudos e coleções que se pretende desenvolver na UMMA. Dessa forma, temos: estudo sobre patrimônio histórico regional, estudo de coleção arquivística, estudo de coleção bibliográfica especial, estudo de coleção museológica, estudo de coleção multimídia, estudo da memória da paisagem, estudo de patrimônio cultural (imaterial), estudo de memória arquitetônica e estudo patrimônio natural. Se observarmos as coleções identificadas nas buscas nos sites institucionais, a estrutura da UMMA inclui mais alguns tipos: do patrimônio histórico regional; estudos do patrimônio natural; da paisagem e cultural (imaterial).

A partir desses dados, indicamos possíveis comparações entre os resultados das buscas nos sites institucionais das universidades federais 
pesquisadas e a estrutura proposta pelo organograma da UMMA da UFSCar. Identificamos, primeiramente, que algumas expressões são comuns a ambas as referências: coleção museológica, bibliográfica e arquitetônica. Já as que apresentam termos diferentes para as coleções são: coleção documental/textual (IFES) e coleção arquivística (UMMA); coleção audiovisual (IFES) e coleção multimeios (UMMA); coleção artística e cultural (IFES) e patrimônio cultural e coleção imaterial (UMMA).

Adicionalmente, foi possível identificar, por meio das análises anteriores, que alguns tipos de coleções estão presentes nos resultados de busca junto às IFES, mas não constam no organograma da UMMA, são elas: as coleções iconográfica, científica e cartográfica. Desse modo, uma possível recomendação é a inclusão dessas coleções na proposta da UMMA, seja como frentes de trabalho ou mesmo como subáreas de coleções existentes. Dessa forma, os resultados, mesmo que de forma parcial, nos mostram como alguns elementos, como no caso as coleções de outras universidades federais, podem vir a contribuir para o processo de desenvolvimento da UMMA na UFSCar.

Da mesma forma, podemos apontar que a UMMA, mesmo com um organograma em fase de elaboração, apresenta outros tipos de documentos, coleções e até patrimônios que se relacionam à memória da instituição, e que podem vir a contribuir como possível referência para outras instituições.

Neste sentido, damos destaque para a incorporação, segundo os moldes da estrutura da UMMA: do patrimônio histórico regional; dos estudos do patrimônio natural e da paisagem. O patrimônio histórico regional está relacionado ao entorno dos municípios no qual há os campi da UFSCar: São Carlos, Sorocaba, Araras e Lagoa do Sino. A identificação do patrimônio histórico regional reflete tanto na universidade quanto na própria região em que se insere. Dessa forma, essa iniciativa pode favorecer a preservação e valorização do patrimônio material e imaterial que, sobretudo, compõem a memória institucional da universidade.

Por sua vez, no caso dos estudos do patrimônio natural e da paisagem, podemos visualizar, por exemplo, no caso da UFSCar no campus de São Carlos, o Cerrado localizado na região Norte; os pinheiros que dividem a região norte e 
sul; o lago que divide o campus, assim como árvores, campos, plantas que fazem parte da história da instituição.

Esses novos estudos podem a vir a contribuir tanto com a criação da UMMA quanto como referência para outras universidades, sejam aquelas que já possuem algum centro de memória, sejam aquelas que venham a criar futuramente elementos para compor, identificar e caracterizar sua memória institucional.

\section{CONSIDERAÇÕES FINAIS}

O objetivo desta pesquisa é refletir sobre os elementos que possam subsidiar a identificação e a preservação da $\mathrm{Ml}$, tendo em vista a consolidação da proposta da Unidade Multidisciplinar de Memória e Arquivo Histórico (UMMA) na UFSCar. Para tanto, toma-se como base o levantamento de informações de universidades federais brasileiras, sobre suas iniciativas relacionadas à Ml.

Identificamos, junto aos sites das IFES, como principais nomenclaturas relacionadas à ideia da Ml: Centro de Informação, Documentação e Arquivo (UFG), Lugares de Memória (UFBA), Memorial (UFC, UFMA), Museu Universitário (UFAC), Divisão de Memória Institucional (UFRJ), Museu (UFLA, UFRGS).

Identificamos que, em sua maioria, esses centros estão vinculados ao Sistema Integrado de Biblioteca (SIBI) e ao Gabinete do Reitor (GR). A subordinação a essas unidades reflete a forma como a memória é percebida pelos gestores, e que tipos de profissionais estão relacionados às suas atividades. No caso do SIBI, há uma tendência maior de envolvimento de profissionais mais especificamente da área de Biblioteconomia. Já os GR podem ser compostos por um grupo mais multidisciplinar, como é o caso da UFSCar.

Também foi possível identificar o predomínio das seguintes coleções: textual/documental, museológica, iconográfica, bibliográfica, científica, cartográfica, audiovisual, arquitetônica, artísticas e culturais. No esboço de organograma apresentado da UMMA, ainda não institucionalizado, todas essas coleções estão presentes, com exceção das coleções iconográfica, científica e 
cartográfica. Para futuros trabalhos, no processo de desenvolvimento da UMMA, sugerimos a incorporação dessas coleções como frentes de trabalho ou até mesmo como subáreas de coleções já existentes, como no caso da coleção iconográfica, que pode ser incorporada como subárea de estudo ou subgrupo de trabalho da coleção arquivística.

Em decorrência dos resultados também foi visível, por meio da análise do organograma da UMMA, a possível contribuição dessa unidade para com outras universidades. Diferentemente das demais iniciativas, a UMMA inclui os seguintes elementos em sua estrutura: o patrimônio histórico regional; os estudos do patrimônio natural e da paisagem. Esses elementos podem vir a ser acrescidos nos centros de memória já existentes, ou em universidades que planejam a criação de seus centros.

\section{REFERÊNCIAS}

CAMARGO, A. M; GOULART, S. Centros de memória: Uma proposta de definição. São Paulo: Edições Sesc São Paulo, 2015.

BRASIL. Decreto ${ }^{\circ} 5.773$, de 9 Maio de 2006. Dispõe sobre o exercício das funções de regulação, supervisão e avaliação de instituições de educação superior e cursos superiores de graduação e sequenciais nos sistema federal de ensino. Diário Oficial da União, Brasília, DF. 2006a.Disponível em: de http://www2.mec.gov.br/sapiens/portarias/dec5773.htm. Acesso em: 30 nov. 2018.

BRASIL Lei no 10.861, de 14 de Abril de 2004. Institui o Sistema Nacional de Avaliação de Educação Superior - SINAES e dá outras providências. Diário Oficial da União, seção 1. Disponível em: http://portal.mec.gov.br/seed/arquivos/pdf/legislacao/decreton57731.pdf. Acesso em: 30 nov. 2018.

BRASIL. Portaria $n^{\circ} 300$, de 30 de janeiro de 2006. Aprova, em extrato, o Instrumento de Avaliação Externa de Instituições de Educação Superior do Sistema Nacional de Avaliação de Educação Superior - SINAES. Diário Oficial da União, n 22, seção I. 2006b. Disponível em: https://www.legisweb.com.br/legislacao/?id=197099. Acesso em: 30 nov. 2018.

DESIDERIO, M.; FERREIRA, A. P. F. Desafios da gestão universitária. In: XVSEGET SIMPÓSIO DE EXCELÊNCIA EM GESTÃO E TECNOLOGIA, 15, 2004, Resende. Anais [...] Resende: AEDB, 2004. Disponível em: 
https://www.aedb.br/seget/artigos2004.php?pag=GP. Acesso em: 30 nov. 2018.

COSTA, L. S. F. Proposta do organograma da UMMA. 2017.

GIL, A. C. Como elaborar projetos de pesquisa. São Paulo: Atlas, 2010.

HALBWACHS, M. A Memória Coletiva. São Paulo: Centauro, 2006

LE GOFF, J. História e memória. Campinas: Ed. Unicamp, 2003.

MATOS, M. T. N. B. Memória Institucional e Gestão Universitária no

Brasil: o caso da Universidade Federal da Bahia. 2004. Tese (Doutorado em

Educação). Universidade Federal da Bahia, Salvador, 2004

SGUISSARDI, V. Universidade, fundação e autoritarismo: o caso da

UFSCar. São Paulo: Estação da Liberdade, 1993.

THIESEN, I. Memória institucional. João Pessoa: Editora UFPB, 2013.

UFSCAR. Universidade Federal de São Carlos (UFSCar). Plano de Desenvolvimento Institucional-PDI, [2004]. A construção do Plano de Desenvolvilmento Institucional. Disponível em:

http://www.pdi.ufscar.br/documentos/plano-de-desenvolvimento-institucionalda-ufscar-.pdf .Acesso em: 30 nov. 2018

UFSCAR. Universidade Federal de São Carlos (UFSCar). Plano de Desenvolvimento Institucional-PDI, [2013]. Versão Final aprovada pelo Conselho Universitário em 20/12/2013. Disponível em: http://www.pdi.ufscar.br/diretrizes-gerais-especificas-e-para-gestao-do-espacofisico. Acesso em: 30 nov. 2018

UFSCAR. Universidade Federal de São Carlos (UFSCar). Apresentação. 2018. Disponível em: https://www2.ufscar.br/a-ufscar/apresentacao. Acesso em: 30 nov. 2018

\title{
THE ROLE OF THE INSTITUTIONAL MEMORY FOR UNIVERSITY MANAGEMENT: CONTRIBUTIONS FOR THE CONSOLIDATION OF UMMA IN UFSCAR
}

\begin{abstract}
Introduction: This paper proposes possible relations between university management and memory. More specifically, it highlights the contribution of Institutional Memory (MI) as a relevant element to sustain management actions. The Federal University of São Carlos (UFSCar), in the context of consolidating its information, communication and memory policy, created in 2017 the Multidisciplinary Memory and Historical Archives Unit. This initiative exemplifies the value of safeguarding Institutional Memory by university management. Objective: The objective of this research is to reflect on the elements that can subsidize the identification and safeguarding of MI, in view of the
\end{abstract}


consolidation of UMMA in UFSCar. Methodology: The methodology adopted was bibliographic, documentary and exploratory. Three types of sources were analyzed: (1) the scientific literature on the subject; (2) institutional documents of UFSCar related to the memory policy and the creation of UMMA; and (3) information on the institutional sites of a set of Brazilian federal universities, regarding the safeguarding of IM. Results: The main elements were: nomenclature, link and collections. The initiatives identified have different nomenclatures, and are linked to different sectors of universities. The collections linked to the IM are varied in format and support. Conclusions: The results obtained illustrate possible contributions to the consolidation of UMMA, as well as this as reference to other universities, demonstrating how the safeguard of the IM can contribute to the creation of strategies linked to the development of the institution.

Descriptors: University Management. Institutional Memory. Federal Universities

\title{
EL PAPEL DE LA MEMORIA INSTITUCIONAL PARA LA GESTIÓN UNIVERSITARIA: CONTRIBUCIONES A LA CONSOLIDACIÓN DE LA UMMA EM UFSCAR
}

\begin{abstract}
RESUMEN
Introducción: Este trabajo propone posibles relaciones entre la gestión universitaria y la memoria. Más específicamente, resalta la constatación de la Memoria Insiticional (MI) como un elemento relevante para sostener acciones de gestión. La Universidad Federal de São Carlos (UFSCar), en el contexto de la consolidación de su política de información, comunicación y memoria, crea en 2017 la Unidad Multidisciplinaria de Memoria y Archivo Histórico. Esta iniciativa ejemplifica la valorización de la salvaguardia de la Memoria Institucional por parte de la gestión universitaria. Objetivo: El objetivo de esta investigación es reflexionar sobre los elementos que puedan subsidiar la identificación y la salvaguardia de la MI, con miras a la consolidación de la UMMA en la UFSCar. Metodología: La metodología adoptada fue de carácter bibliográfico, documental y exploratorio. Se analizaron tres tipos de fuentes: (1) la literatura científica sobre el tema; (2) documentos institucionales de la UFSCar relacionados con la política de memoria y la creación de la UMMA; y (3) informaciones de los sitios institucionales de un conjunto de universidades federales brasileñas, en lo que se refiere a la salvaguardia de la MI. Resultados: Como principales elementos, fueron identificados: nomenclatura, vínculo y colecciones. Las iniciativas identificadas poseen nomenclaturas distintas, y están vinculadas a diferentes sectores de las universidades. Las colecciones vinculadas a MI son variadas en formato y soporte. Conclusiones: Los resultados obtenidos ilustran posibles contribuciones para la consolidación de la UMMA, así como de ésta como referencia para otras universidades, demostrando cómo la salvaguardia de la Ml puede contribuir a la creación de estrategias vinculadas al desarrollo de la institución.
\end{abstract}

Descriptores: Gestión Universitaria. Memoria Institucional. Universidades Federales 